\title{
National responsibilities for conserving habitats - a freely scalable method
}

\author{
Dirk S. Schmeller ${ }^{1,2}$, Andrea Maier², Doug Evans ${ }^{3}$, Klaus Henle² \\ I UFZ - Helmholtz Centre for Environmental Research, Department of Conservation Biology, Leipzig, Ger- \\ many 2 Station d'Ecologie Expérimentale du CNRS, Moulis, France 3 EEA-European Topic Centre on Biolo- \\ gical Diversity (ETC/BD), Muséum National d'Histoire Naturelle, Paris, France
}

Corresponding author: Dirk S. Schmeller(ds@die-schmellers.de)

Academic editor: S. Lengyel | Received 17 July 2012 | Accepted 21 September 2012 | Published 17 December 2012

Citation: Schmeller DS, Maier A, Evans D, Henle K (2012) National responsibilities for conserving habitats - a freely scalable method. Nature Conservation 3: 21-44. doi: 10.3897/natureconservation.3.3710

\begin{abstract}
Conservation of habitats is a major approach in the implementation of biodiversity conservation strategies. Because of limited resources and competing interests not all habitats can be conserved to the same extent and a prioritization is needed. One criterion for prioritization is the responsibility countries have for the protection of a particular habitat type. National responsibility reflects the effects the loss of a particular habitat type within the focal region (usually a country) has on the global persistence of that habitat type. Whereas the concept has been used already successfully for species, it has not yet been developed for habitats. Here we present such a method that is derived from similar approaches for species. We further investigated the usability of different biogeographic and environmental maps in our determination of national responsibilities for habitats. For Europe, several different maps exist, including (1) the Indicative European Map of Biogeographic Regions, (2) Udvardy's biogeographic provinces, (3) WWF ecoregions, and (4) the environmental zones of Metzger et al. (2005). The latter is particularly promising, as the map of environmental zones has recently been extended to cover the whole world (Metzger et al. in press), allowing the application of our methodology at a global scale, making it highly comparable between countries and applicable across variable scales (e.g. regions, countries). Here, we determined the national responsibilities for 71 forest habitats. We further compared the national responsibility class distribution in regard to the use of different reference areas, geographical Europe, Western Palearctic and Palearctic. We found that the distributions of natural responsibility classes resembled each other largely for the different combinations of reference area and biogeographic map. The most common rank in all cases was the "medium" rank. Most notably, with increasing size of the reference area, a shift from alloca-
\end{abstract}

Copyright Dirk S. Schmeller et al. This is an open access article distributed under the terms of the Creative Commons Attribution License 3.0 (CC-BY), which permits unrestricted use, distribution, and reproduction in any medium, provided the original author and source are credited. 
tions to a basic rank to allocations to a medium rank (from 1:4 to 1:1) was observed. The least frequent rank was the "very high" category. The methodology to determine national responsibilities presented here is readily applicable to estimate conservation responsibilities for habitats of the EU25 countries. It should be based on the environmental zones map and should use Europe as the reference area. It then provides a tool to allocate funds, direct conservation actions in the most sensible way, and highlight conservation-relevant data gaps.

\section{Keywords}

Conservation tools, environmental zones, habitat conservation, national responsibility, prioritization, scaling

\section{Introduction}

Despite numerous legal commitments, resources for habitat conservation remain scarce, requiring a prioritization of conservation efforts. In contrast to species, for which a range of different approaches have been developed (Schnittler et al. 1994, Couturier 1999, Schnittler and Günther 1999, Beissinger et al. 2000, Carter et al. 2000, Coates and Atkins 2001, Keller and Bollmann 2001, 2004, Schnittler 2004, Brooks et al. 2006, Schmeller et al. 2008a, b, c), fewer methods are available for habitats (but see Schnittler et al. 1994, Essl et al. 2002, Traxler et al. 2005). However, European countries are responsible for conservation of natural and semi-natural habitats, as they have adopted the obligations of the Convention on Biological Diversity (CBD). Within the European Union, the principal legal instrument for habitat conservation is the 1992 Habitats Directive (92/43/EEC) which has been transposed into national law by all 27 Member States. The directive is an EU implementation of the Bern Convention (Convention on the Conservation of European Wildlife and Natural Habitats; see also Evans 2012). At the European Council in Göteborg in 2001, the Heads of State made a commitment to "halt biodiversity loss by 2010 " and the EU has adopted a biodiversity strategy with clear targets for habitat conservation (CEC 2006, 2012).

Priority areas of conservation importance were defined using the concept of biological hotspots for large biomes (Mittermeier et al. 1998). At finer geographical scales, red lists are the most commonly used tool for conservation assessment as they explain the complex phenomenon "endangerment" in a simple way (The Nature Conservancy 1988, IUCN 1996, IUCN 2001), granting high public acceptance (Schnittler and Günther 1999). The resulting threat status is also taken as a measurement for conservation priorities. However, red lists may at best be a suboptimal tool for setting conservation priorities in a country or region as the threat status does not always reflect actual conservation needs (Gärdenfors 2000, 2001, Mehlman et al. 2004, Eaton et al. 2005). That is especially true from a subsidiary point-of-view, from which it is clearly more desirable to focus national conservation efforts on the habitat types centred in the respective country. As a response, the concept of national responsibility as a complementary tool was developed for species (Schnittler et al. 1994, Schnittler and Günther 1999, Schnittler 2004, Schmeller et al. 2008c). 
The assessment of national responsibilities covers the notion of the importance of a region for the conservation of biodiversity in respect to its irreplaceability (Brooks et al. 2006). Hence, national responsibility serves as a proxy for measuring the probability of global persistence for a given habitat, when a habitat of the focal area (e.g. nation or region) is lost. Hence, if the disappearance of a habitat type in the focal nation affects the global persistence particularly strongly, a nation's responsibility for that habitat is high or even very high. The nation's responsibility for a habitat would be considered low, if overall persistence of a habitat is not affected by the loss in that nation. Therefore, determination of national responsibility permits to emphasise international obligations of conservation that may not be obvious on a local level or by using national red lists only. Although the concept has already been used successfully for species, it has, with two exceptions for Europe, not yet been developed for habitats. National responsibility for habitats has been evaluated within the Red List of biotopes of Austria (Essl et al. 2002, Traxler et al. 2005), using the system developed by Schnittler et al. (1994) and for Annex I habitats of the Habitats Directive. However, no information is available on the methodology and the data used (presumably expert opinion; Henle et al. unpublished). Though habitats for which Europe has a high conservation responsibility should receive high priority, each EU country is equally obliged to conserve habitats listed on the Annex I of the Habitats Directive (Council Directive 92/43/ EEC; http://eur-lex.europa.eu/LexUriServ/LexUriServ.do?uri=CELEX:01992L004320070101:EN:NOT).

The goal of this contribution is the presentation of a new method to determine national responsibilities for habitats which has been derived from a similar method for species (Schmeller et al. 2008a). We discuss limitations caused by different classifications of habitat types and develop the method in the context of different maps of biogeographical regions and environmental zones. Combining the national responsibility results with red lists or other lists reflecting the conservation status (e.g. status of habitats from reporting required by Article 17 of the Habitats Directive) will allow to determine conservation priorities and/or conservation actions and help in sharing the limited resources in observing and conserving biodiversity. We illustrate the approach for the 71 forest habitat types listed on Annex I of the Habitats Directive.

\section{National responsibility method for habitats}

The method to determine national responsibilities for habitats comprises three decision steps. Firstly, the habitat unit is defined; secondly, the distribution pattern of a habitat is determined, meaning its range within and across biogeographic and environmental regions (Figure 1). We used three categories (local, regional, wide), which will be defined below. The distribution pattern of a habitat is central for the assessment of national responsibilities because it measures the importance of the habitat within a focal area. The variation in distribution patterns in relation to biogeographic zones reflects the adaptability of the habitat to different climatic and environmental 


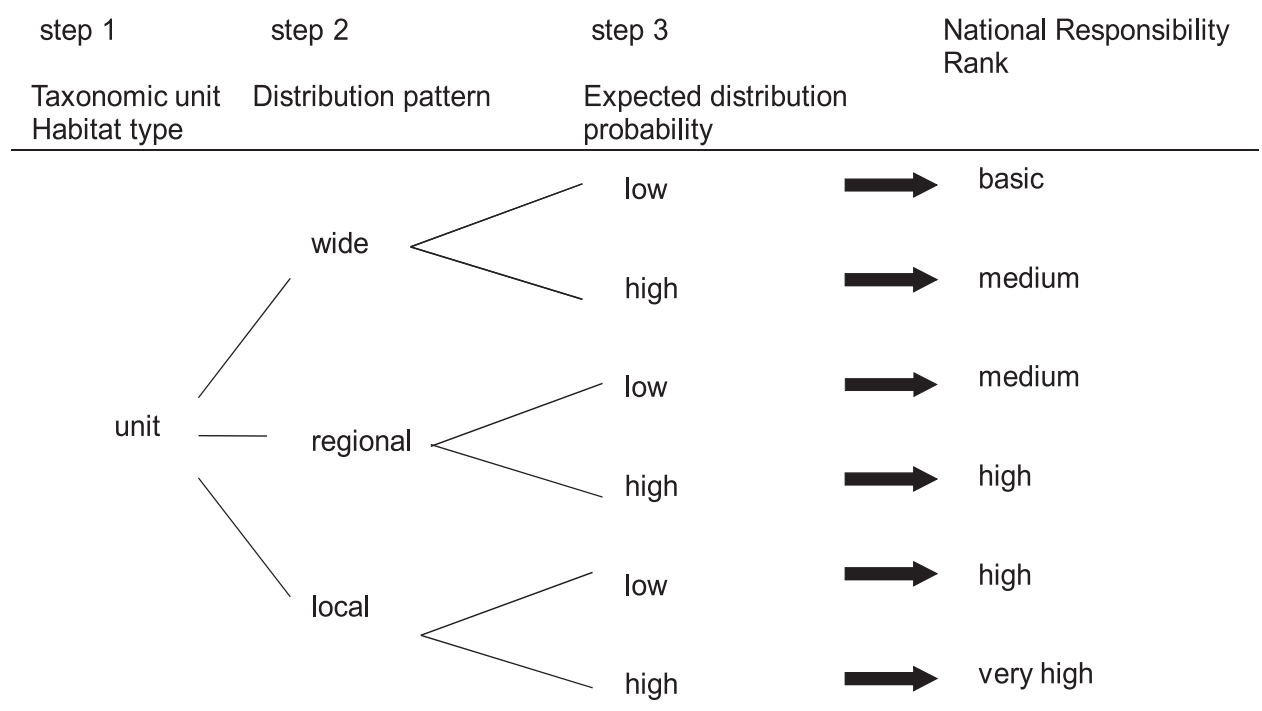

Figure I. Decision tree for the determination of national responsibilities.

conditions. Therefore, a widely distributed habitat can be assumed to be more robust against environmental change, whereas habitats found only in one or two biogeographical regions may face higher pressure of disappearance due to limited adaptability and due to natural and anthropogenic catastrophic events. Our method also takes into account that different parts within a distribution area may play different roles for the overall conservation of a taxon, habitat, or a species (Hanski et al. 1995, Brooks et al. 2006). For example, areas with high quality examples of a habitat type are usually small and rare, with the result that some parts of a habitat's distribution range are more important for the global persistence of a habitat type and the species dependent on that habitat than others, hence having a high international importance for conservation (Schmeller et al. 2008c). To determine the international importance of a localized habitat type for its global persistence, existing methods used several range-based criteria, such as proportional distribution, relative abundance, or location of the distribution center (Schnittler 2004, Schmeller et al. 2008c). Here, we focus on distribution pattern (step 2) and proportional distribution (step 3). The third step determines the importance of a habitat distribution within a focal area as compared to the total distribution or reference area, determining the expected and observed distribution of a habitat, allowing an adaptation to different geographic scales. The distribution pattern and the expected value of occurrence together reflect the importance of a focal area for the global persistence of a habitat. The combination of these 3 steps results in 4 classes of national responsibility (Figure 1). Habitats falling within the same classes should be treated equally in regard to their conservation, as the currently available data is too coarse to make finer adjustments of the categories with less information loss. The application of each of these three steps, while generally straightforward, needs to take several issues into consideration. 


\section{Step 1: Habitat type}

Habitats have both an inherent variability and variations in how they are interpreted from country to country, and sometimes between regions in the same country (Evans 2010). This means that an EU member state or any other country may be the only country where a subtype occurs even though the habitat itself is very widespread. This is an important point, when interpreting the results of a national responsibility assessment.

Definitions also differ between international organizations, such as FAO, CBD, and UNFCCC (Schoene et al. 2007), and between non-EU European countries, e.g. for forests (EEA 2006). In these definitions height, tree density, area, and species composition play a major role and definitions are far from being standardized (Hall et al. 1997). In Europe differences also exist between countries in defining grazing land; in some countries heath lands (low scrub) are included, in others they are excluded, depending on farming practice. These definitions are important when assessing forest decline, land conversion, or $\mathrm{CO}_{2}$ sequestration (Bunce et al. 2010), and national responsibilities. These differences are also visible from the wide range of existing phytosociological vegetation classifications (e.g. Becking 1957, Tichý 2002, Jennings et al. 2009). Phytosociology has had an important influence on the Habitats Directive with some two thirds of the habitats of Annex I having a reference to a syntaxa either in the name or definition. Phytosociology has also been important in the implementation of the directive in most EU countries, as shown by e.g. Biondi et al. (2012). Nonetheless, many nations apply a detailed local habitat classification, such as Germany (the German biotope classification: Riecken 2006) and Hungary (Hungarian National Habitat Classification System Á-NÉR: Fekete et al. 1997, Molnár et al. 2007).

National habitat classifications are usually structured in a hierarchical order consisting of subclasses, which allows a detailed distinction of habitat types dependent on several variables. For example, the German classification, which was used to compile the Red List of German habitats (Riecken 2006), divides deciduous forests in several sub-classes according to local edaphic characteristics, water dependency, site elevation, or species composition. In this way, parameters are interrelated with each other and deciduous forest types are thus presented in a hierarchical order, which allows increasingly detailed distinctions when downscaling from the broadest class to a finer subclass. However, the application of national habitat classifications on surveying habitats leads to distribution information, which is coherent only within national boundaries. Detailed international habitat classifications have been developed for specific habitat groups, such as Baltic Sea habitats or wetlands, (e.g. HELCOM habitat classification 1998, Ramsar Classification System for Wetland Types 2009). However, in order to determine national responsibilities for all habitat groups, a unified classification including all habitat types occurring within the focal geographic area is required.

International classifications, which are not restricted to specific habitat groups and covering a larger geographic range, have been published for Europe and the Palearctic. The CORINE (CORINE: Coordinated Information on the Environment; Moss and Wyatt 1994) program which started in the 1980s has produced classifications of land use and of 
biotopes. CORINE Land Cover uses remote sensing to produce land cover maps at regular intervals using a typology with 44 units, whilst the CORINE biotopes classification distinguishes habitats at a finer scale (Devillers et al. 1991, Moss and Wyatt 1994). The maps from CORINE Land Cover are not sufficiently detailed to be of use for assessing national responsibilities. For example only three types of natural forests are distinguished in comparison to 71 in the Habitats Directive. The CORINE biotopes classification is sufficiently detailed but there is no corresponding data on distribution of the habitat types.

The European Nature Information System (EUNIS; eunis.eea.europa.eu/) provides a database on habitats, species and protected areas which is built on a hierarchical habitat classification (Davies et al. 2004). EUNIS aims to provide a comprehensive classification for European habitats, including a framework of descriptions using habitat parameters and presents information on habitats including descriptions, cross-references with other classification systems and gives some distribution data based on protected sites from which the habitat has been reported. At present, habitat distribution data available from EUNIS is not sufficient for use to determine national responsibility for most habitats.

Annex I of the Habitats Directive lists habitats for which Sites of Community Interest (SCI) must designate sites as part of the NATURA 2000 network as SACs (Evans 2012) and Article 17 of the European Habitats Directive requires all Member States to monitor and report on their conservation status. Although Annex I is not a classification (the habitats come from several classifications, see Evans 2006, 2010, Bunce et al. 2012), it does include a wide range of natural and semi-natural habitats. Reports from the 2nd reporting period (2001-2006) are available (ETC/BD EIONET webtool at http://biodiversity.eionet.europa.eu/article17/habitatsreport/, ETC/BD 2008b and EEA 2009), including assessments of the conservation status of habitats. The Article 17 database (http://www.eea.europa.eu/data-and-maps/data/article-17-database-habitatsdirective-92-43-eec) provides information on distribution areas of the habitat types reported by Member States. The national reports are in a variety of formats, but a harmonized set of distribution maps, based on a $10 \mathrm{~km} \times 10 \mathrm{~km}$ grid prepared by the ETC/ $\mathrm{BD}$, is available. At present the Article 17 database represents the most extensive dataset for habitat distribution and conservation status in the European Union. Although there are many problems associated with the interpretation of the habitats listed in Annex I (Evans 2010, Evans 2012), which can result in unevenness between Member States, basic distribution data gathered under the same framework across the EU25 is available. Therefore, at present the list of 231 habitat types of the Habitats Directive presents the only habitat dataset backed with reasonable data on distribution and extent with which to test the methodology of national responsibilities. The next update of the Article 17 database is due in 2015 and will then include data from all 27 EU Member States.

\section{Step 2: Distribution pattern}

In the second step, the distribution pattern of the habitat unit is determined. Generally, the distribution pattern may serve as an approximation of the ability of a habitat 
to cope with threat factors, similar to a species' distribution pattern in relation to environmental conditions (e.g. Wiens et al. 1997, McIntyre and Wiens 1999). Hence, the distribution pattern provides information about suitable environments for habitats.

For determining the distribution pattern, the choice of the biogeographical map needs to be considered. For the assessment of habitat distribution patterns across biogeographic regions, we have examined the following maps, (1) the Indicative European Map of Biogeographic Regions (hereafter IEMB; EEA 2006, ETC-BD 2006), (2) Udvardy's biogeographic provinces (Udvardy 1975), (3) World Wide Fund for Nature) (WWF) ecoregions (Olson et al. 2001a), and (4) the environmental zones of Metzger et al. (2005; hereafter ESE).

The IEMB was produced to define the biogeographical regions mentioned in Art.1 c) (iii) of the Habitats Directive (Figure 2) and is the official geographical framework for which Sites of Community Interest are designated and for monitoring and reporting on habitat types (Article 17 reporting). The IEMB was formally adopted by the Habitats Committee, the body established to oversee the implementation of the Habitats Directive. It is based on interpretations of the "Map of Natural Vegetation of the Member Countries of the European Community and of the Council of Europe" and the "Map of the Natural Vegetation of Europe" (Noirfalse 1987, Bohn et al. 2000, ETC/CB 2006) with each mapping class allocated to a biogeographical region or a group of azonal habitats. The resulting map was then generalized and in some cases adjusted for administrative convenience. The map is also used for the Emerald network, a network of protected areas under the Bern Convention. Since the SWG decided not to define sub-regions but to produce a biogeographic map at a smaller scale (1:10 million), the natural vegetation map needed to be aggregated and generalized. Vegetation classes were allocated to biogeographic regions. In the case an attribution to one particular region was impossible this area was incorporated into neighboring biogeographic regions. The delineation of regions was carried out for the territory of the EU12. The European biogeographic map was further expanded, 1) as more Member States joined the EU and, 2) to provide a biogeographic map of "PanEurope" within the framework of the Emerald network. The Emerald network under the Bern convention is a geographical complement of the Natura 2000 network in non-EU countries (see e.g. Tillmann 2005). The expansion of the biogeographic map was generally used by Member States to suggest modifications of border delineations (ETC-BD 2006). Politically induced amendments were carried out e.g. in Germany for the border delineation between Atlantic and Continental, as well as Alpine and Continental regions. Furthermore, Lithuania was placed entirely in the Boreal biogeographic region despite the fact that approximately half of the country is regarded to lie within the Continental biogeographic region.

In the 1960ies, the goal of establishing a worldwide network of natural reserves encompassing representative areas of the world's ecosystems was widely supported (Whittaker et al. 2005; Kleft and Jetz 2010). In this context, the IUCN commissioned the biogeographer Udvardy to develop and refine the method of distinguishing biotic provinces (Udvardy 1969) incorporating Dasmann's (Dasmann 1972, 


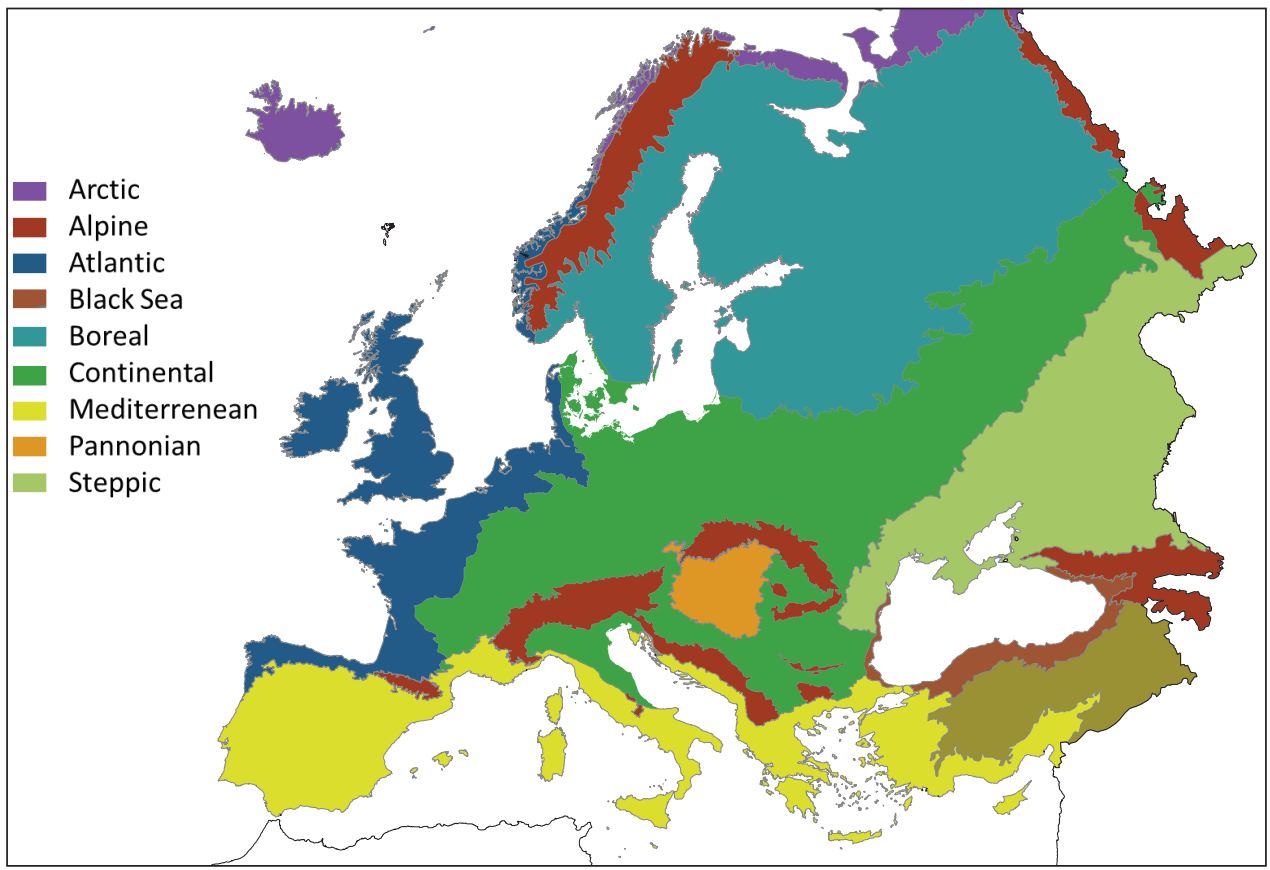

Figure 2. Indicative European Map of Biogeographic Regions (EEA 2006). For further information please see http://ec.europa.eu/environment/nature/natura2000/sites_hab/biogeog_regions/index_en.htm

Dasmann 1974) biotic classifications of faunal regions and vegetation zones (Whittaker et al. 2005; Table 1).

A third map, the WWF ecoregions map (Dinerstein et al. 1995, Olson et al. 2001b; Table 1) was developed since no biodiversity map with a sufficient biogeographic resolution existed to accurately reflect the world's distribution of biotic communities. Ecoregions are defined as relatively large units of land where characteristic species and habitats occur or did occur prior to land use changes. The WWF map of ecoregions was criticized for the lack of scientific explicitness, transparency, and repeatability of methods (Whittaker et al. 2005), and for missing tests of border delineations of ecoregions (Magnusson 2004).

The Environmental Stratification of Europe (hereafter called ESE; Metzger et al. 2005) was generated to produce a statistical stratification of the environment, which is suitable for stratified random sampling of ecological resources and the selection of sites for representative studies. Previous methods to statistically stratify the environment suffered from limitations, such as a coarse resolution or a small area in focus (Metzger et al. 2005), the ESE uses a resolution of $1 \mathrm{~km} \times 1 \mathrm{~km}$ and covers Europe as a larger focal area. The stratification was based on twenty environmental variables, examined in earlier studies (see e.g. Bunce et al. 2010). These variables were derived from elevation data acting as surrogates of geomorphologic information, climatic variables, and indicators of northing and oceanity. A statistical clustering led to 84 environmental strata, which can be aggregated into 13 environmental zones (Figure 3; Table 1). The statisti- 
Table I. Comparison of the four biogeographic maps.

\begin{tabular}{|c|c|c|c|c|}
\hline & Udvardy's system & $\begin{array}{c}\text { Indicative European } \\
\text { Map of Biogeographic } \\
\text { Regions (IEMB) } \\
\end{array}$ & $\begin{array}{l}\text { Environmental } \\
\text { Zones (ESE) }\end{array}$ & WWF Ecoregions \\
\hline Development & \begin{tabular}{|} 
Developed for the \\
IUCN between \\
$1970-1975$ by \\
Dasman and Udvardy \\
(Udvardy 1975)
\end{tabular} & $\begin{array}{l}\text { Scientific Working } \\
\text { Group of the Habitats } \\
\text { Directive, } \\
\text { (ETC-BD 2006) }\end{array}$ & Metzger et al. (2005) & $\begin{array}{l}\text { World Wildlife } \\
\text { Fund for Nature, } \\
\text { Olsen et al 2001a }\end{array}$ \\
\hline $\begin{array}{c}\text { Name of } \\
\text { regions }\end{array}$ & $\begin{array}{l}\text { Biogeographic } \\
\text { provinces }\end{array}$ & Biogeographic regions & $\begin{array}{l}\text { Environmental } \\
\text { zones }\end{array}$ & Ecoregions \\
\hline Basic principle & $\begin{array}{c}\text { Combining ecoclimatic } \\
\text { features and } \\
\text { taxonomic differences, } \\
\text { biogeographic } \\
\text { provinces delineated } \\
\text { by faunal regions and } \\
\text { climax vegetation type }\end{array}$ & $\begin{array}{c}\text { Based on "Map of } \\
\text { Natural Vegetation" } \\
\text { (Noirfalse 1987) \& Map } \\
\text { of Natural Vegetation } \\
\text { of Europe. Vegetation } \\
\text { units were allocated to } \\
\text { biogeographical regions } \\
\text { followed by generalization } \\
\& \text { simplication }\end{array}$ & $\begin{array}{c}\text { Climatic } \\
\text { stratification of the } \\
\text { environment of } \\
\text { Europe, based on } \\
\text { statistical clustering } \\
\text { of environmental } \\
\text { variables }\end{array}$ & $\begin{array}{l}\text { Delineations } \\
\text { regarding species } \\
\text { compositions, } \\
\text { ecological } \\
\text { dynamics, shared } \\
\text { environmental } \\
\text { conditions } \\
\text { and, ecological } \\
\text { interactions } \\
\end{array}$ \\
\hline $\begin{array}{l}\text { Number of } \\
\text { European } \\
\text { regions }\end{array}$ & 14 & 8 & 13 & 44 \\
\hline $\begin{array}{l}\text { Number of } \\
\text { (land) regions } \\
\text { relevant for } \\
\text { forest habitats }\end{array}$ & 13 & $\begin{array}{l}7 \text { regions for EU25, } 9 \\
\text { for EU27, and } 11 \text { for } \\
\text { Pan Europe. }\end{array}$ & 12 & 40 \\
\hline Advantages & $\begin{array}{c}\text { Consistent algorithms, } \\
\text { not politically } \\
\text { influenced }\end{array}$ & $\begin{array}{l}\text { Widely accepted by } \\
\text { policy makers }\end{array}$ & \begin{tabular}{|l} 
Scientific statistical \\
approach not \\
politically \\
influenced, based \\
directly on climatic \\
variables, not \\
vegetation
\end{tabular} & $\begin{array}{l}\text { Not politically } \\
\text { influenced }\end{array}$ \\
\hline Weaknesses & $\begin{array}{c}\text { Vegetation as } \\
\text { determining factor }\end{array}$ & $\begin{array}{c}\text { Border adjusted } \\
\text { for administrative } \\
\text { convenience vegetation } \\
\text { as determining factor }\end{array}$ & & $\begin{array}{l}\text { Large number } \\
\text { of regions, } \\
\text { inconsistent } \\
\text { delineation, based } \\
\text { on vegetation } \\
\end{array}$ \\
\hline
\end{tabular}

cal analysis provides robust divisions based on the combination of variables even in regions where large-scale continuous gradients occur (e.g. Northern Spain). The statistical approach is reproducible and independent of personal bias (Metzger et al. 2005). Currently, the environmental stratification is used for several applications, including as units for summary reporting (Metzger et al. 2008), for estimation of potential areas for cultivation of bio-energy crops, or for prediction of future crop yields (Ewert et al. 2005). The approach is currently being extended to give an environmental stratification of the world (Metzger et al. 2011, in press).

Table 1 summarizes the characteristics, advantages, and disadvantages of the four maps. Vegetation is used as the main determining factor for delineating regions in all 


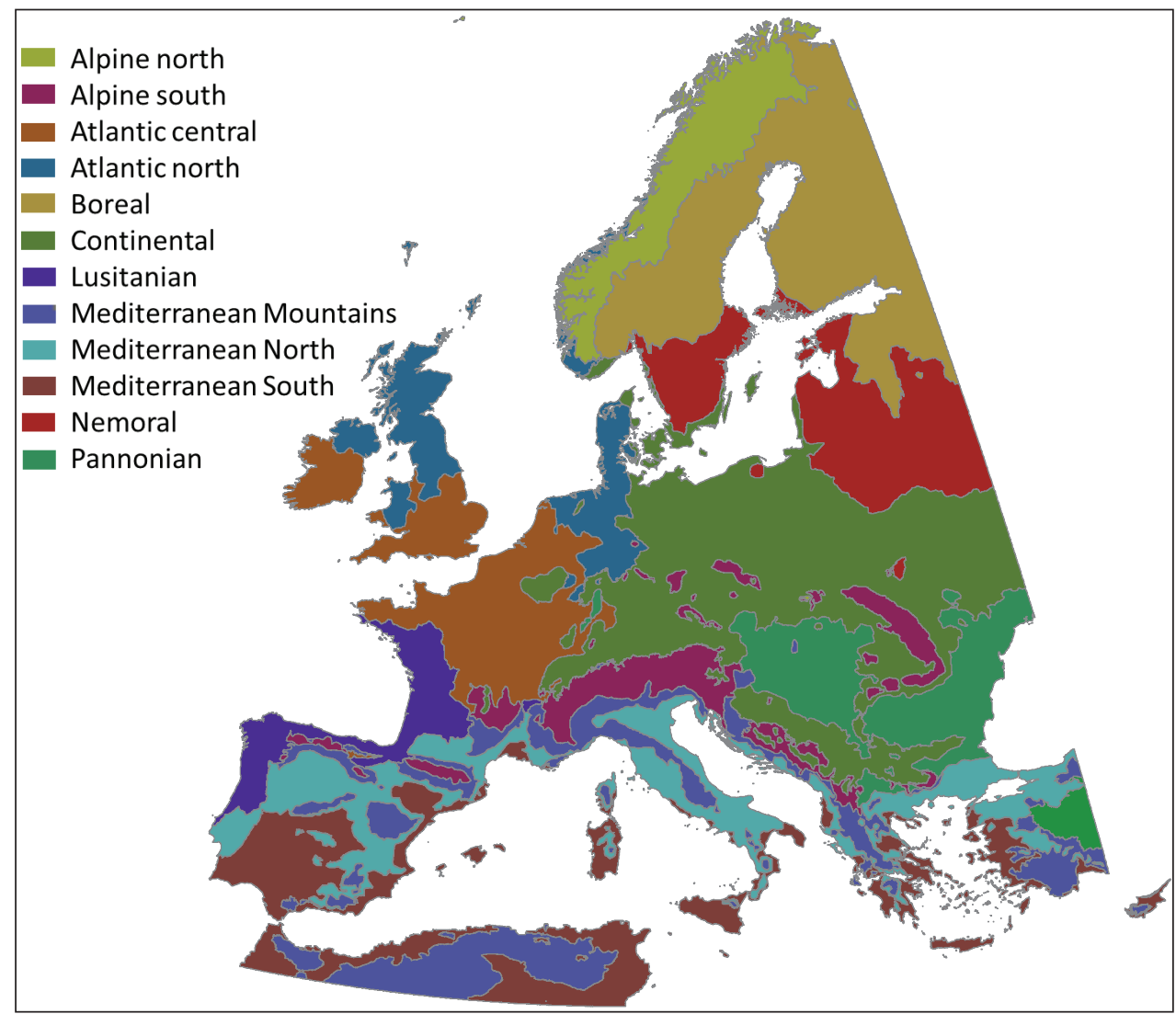

Figure 3. Environmental Zones of Europe (Metzger et al. 2005).

except the environmental stratification zones of Metzger et al. (2005), which is based on climatic factors. The latter is the only map that is founded on a statistically rigorous stratification though Udvardy's map also uses a consistent algorithm to delineate regions. In the IEMB borders of regions were adjusted due to requests of Member States to reduce the administrative load, thus not always using environmentally consistent borders. However, it has the advantage that it is widely accepted politically. It also has the coarsest resolution, whereas the WWF ecoregions recognize the largest number of different regions within Europe (see Table 1 for details). A comparison of the different maps (see Annex Table A1-3), shows marked differences between them. For most zones the correspondence among the four maps is limited (often less than 75\%).

\section{Distribution pattern and the different biogeographic and environmental maps}

Comparison of the different biogeographic maps has shown differences between each of them, e.g. the number of biogeographic regions or environmental zones is not the same. Thus, habitats may occur in more zones when using fine-grained biographic 
zones than when using coarser grained maps. Moreover, as environments rarely have abrupt natural borders, any stratification will sometimes allocate similar environments on both sides of a border into different categories. This can result in habitats with small distributions occurring in 2 or more zones. For example, habitat 91R0, "Dinaric dolomite Scot's pine forest (Genisto januenis-Pinetum)", with a reported distribution area of $2885 \mathrm{~km}^{2}$ belongs to the 10 habitats with the smallest distribution ranges but is found in two zones of the IEMB map. The definition of classes of the distribution pattern used should reflect these aspects in such a way that the distribution of habitats across responsibility classes should not deviate too strongly from each other when different biogeographic concepts are used and should not allocate habitats with a small distribution area into a wide category. Here, we develop the categories for two maps, the ESE, as it has been widely accepted in habitat monitoring and is based on objective criteria for the delimitation of the different environmental zones, and the IEMB map, which has a legal status.

For the IEMB map, a local distribution pattern is attributed to habitats occurring in patches belonging to a single biogeographic region. Regional are habitats with a up to two-thirds of the distribution area in one biogeographic region. Wide refers to habitats with a distribution spanning two or more biogeographic regions.

For the ESE, a local distribution pattern is attributed to habitats occurring in only one environmental zone. Habitats have a regional distribution, if they are restricted to two neighboring environmental zones. All habitats with a distribution spanning three or more environmental zones were considered habitats with a wide distribution.

\section{Step 3: Expected distribution probability}

The third step of the proposed national responsibility method is to determine the expected value of occurrence $\left(\mathrm{OV}_{\text {exp }}\right)$ in the focal area (e.g. a country). Following the suggestion of Keller and Bollmann $(2001,2004)$, first the expected distribution probability $\left(\mathrm{DP}_{\text {exp }}\right)$ and the observed distribution probability $\left(\mathrm{DP}_{\mathrm{obs}}\right)$ are compared. $\mathrm{DP}_{\exp }$ is calculated as the ratio of the total distribution area of the habitat and the size of the reference area, while $\mathrm{DP}_{\mathrm{obs}}$ is obtained as the ratio of the distribution range of the habitat in a focal region (country) to the total size of the focal region. If the latter value is above double the expected distribution probability, the expected value of occurrence of a habitat in the focal area is high, whereas below it is classified as being low $\left(\mathrm{DP}_{\text {obs }}>2^{*}\right.$ $\mathrm{DP}_{\exp }$ P $_{\text {Oxp }}=$ High; $\mathrm{DP}_{\text {obs }}<2^{*} \mathrm{DP}_{\exp }$ P $_{\text {OV }}=$ Low)

The reference area should comprise the potential distribution area of a habitat in order to correctly determine whether the habitat distribution within a focal country plays a crucial role for the global persistence of a habitat or not. The main difficulty with this approach is data availability on habitat distribution and the different definitions, which exist world-wide. Also, different habitats will have different distributional limits so that whatever the reference area is some habitats will be included only incompletely or marginally. Several reference areas might be considered appropriate 
for European habitat types, 1) geographical Europe (Ural as eastern border; extent 10.936.779 $\mathrm{km}^{2}$ ), 2) the Western Palearctic (Europe, the Middle East, and North Africa, $33.225 .342 \mathrm{~km}^{2}$ ), or 3) the Palearctic (including Europe, northern Africa, Russia, northern and central Asia, covering $54.244 .453 \mathrm{~km}^{2}$, see Kreft and Jetz 2010 for other potential reference areas outside of a European context).

Another important decision in this last step concerns the cut-off value. When can we consider an observed distribution probability as high or low? If the observed probability is twice as high as the expected value does this count as high? Given that the Agenda 2010 and the Aichi targets oblige European Member States to conserve a significant part of its biodiversity in each biogeographic region, this third and last step, as suggested here, should be conservative and accounts for the international importance of a habitat in a country and within a biogeographic region.

National responsibilities for EU forest habitats

As a test of the proposed methodology, we determined national responsibilities across geographical Europe, the Western Palearctic region, and the Palearctic region as reference areas and the ESE and IEMB maps for the 71 Annex I forest habitat types occurring in the EU25 (Table A4). We assessed national responsibilities using spatial datasets giving distribution of the habitats (EEA 2009). The habitat distribution across biogeographic regions of both biogeographic maps was created by overlaying shapefiles with a biogeographic map using the "Identify" tool from the "Analysis tools" in ArcGIS v10 (Esri), which attributes names of the biogeographic regions to the habitat distribution polygons. Polygons stretching over several regions were cut at biogeographic borders and each new polygon was attributed the name of the underlying region. Afterwards, we calculated the area of the habitat distribution polygon for the biogeographic region(s) where it occurred.

\section{Results}

The highest number of forest habitat types was found in Italy (36 out of $71 ; 51 \%$ ) followed by France $(29,41 \%)$, Spain $(28,39 \%)$ and Greece $(27,38 \%$; Figure 4$)$. The number of habitat types was positively correlated with the size of the country $\left(R_{23}=\right.$ $0.702 ; p<0.001)$.

The distributions of natural responsibility (NR) classes largely resembled each other for the different combinations of reference area and biogeographic map. The most common rank in all cases was "medium"; the rank "very high" was the least common (Figure 5). We compared the number of NR-ranks of the six different combinations of reference area and biogeographic map using the combination Europe as reference area and the IEMB map as a baseline. The least affected rank in all the different assessments was the rank "very high", which showed an $N$ between 22 and 24. The largest differences were found for the "basic" rank. The number of this rank ranged between 59 and 134 (Figure 5). With increasing size of the reference area, a shift from allocations to a basic rank to allocations to a medium rank (from 1:4 to 1:1) was observed (Figure 6; 


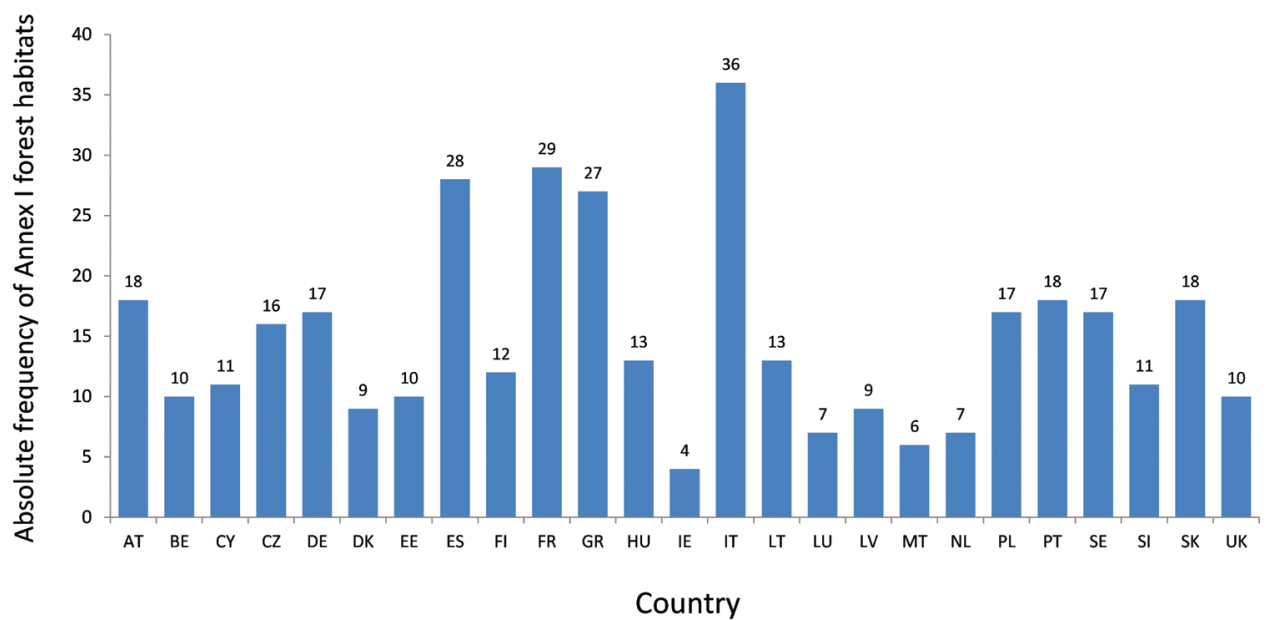

Figure 4. Number of forest habitat types as defined in the Annex I of the Habitats Directive by European country. The countries are abbreviated following the two-letter convention of the international community (ISO 3166-1 alpha-2 codes; AT = Austria, BE = Belgium, CY = Cyprus, CZ = Czech Republic, DE = Germany, DK = Denmark, EE = Estonia, ES = Spain, FI = Finland, FR = France, GR = Greece, $\mathbf{H U}=$ Hungary, IE = Ireland, IT = Italy, LT = Lithuania, $\mathbf{L U}=$ Luxembourg, $\mathbf{L V}=$ Latvia, $\mathbf{M T}=$ Malta, $\mathbf{N L}=$ Netherlands, $\mathbf{P L}=$ Poland, $\mathbf{P T}=$ Portugal, $\mathbf{S E}=$ Sweden, $\mathbf{S I}=$ Slovenia, $\mathbf{S K}=$ Slovakia, $\mathbf{U K}=$ Great Britain $)$.

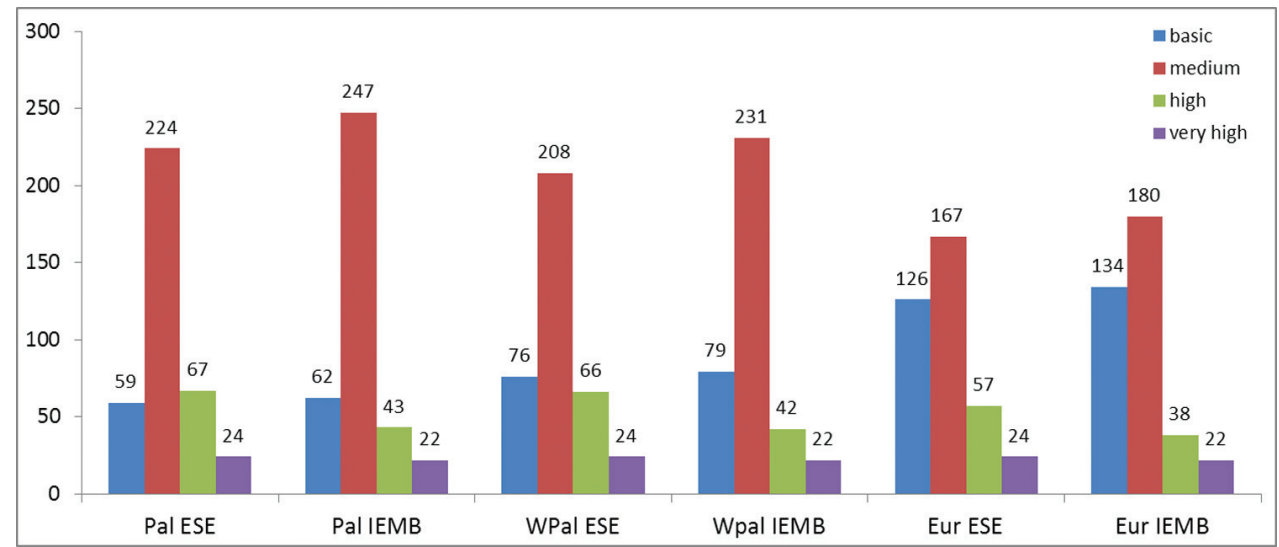

Figure 5. Distribution of National Responsibility ranks in the different combinations of reference area and biogeographic map. Reference area: $\mathbf{P a l}=$ Palearctis, $\mathbf{W P a l}=$ Western Palearctis, Eur $=$ geographic Europe; maps: ESE = Environmental zones, IEMB = IEMB biogeographic map.

Figure 7). The comparison of the allocation of habitats to responsibility classes between the two different biogeographic maps ESE and IEMB showed a shift from lower to higher ranks for all three reference areas, especially a shift from the ranks "medium" toward "high" (Figure 7), for the finer grained ESE map.

Comparing the two biogeographic maps by country reveals shifts mainly from medium to high ranks for northern countries (EE, LV, LT, FI, SE) and countries in the 


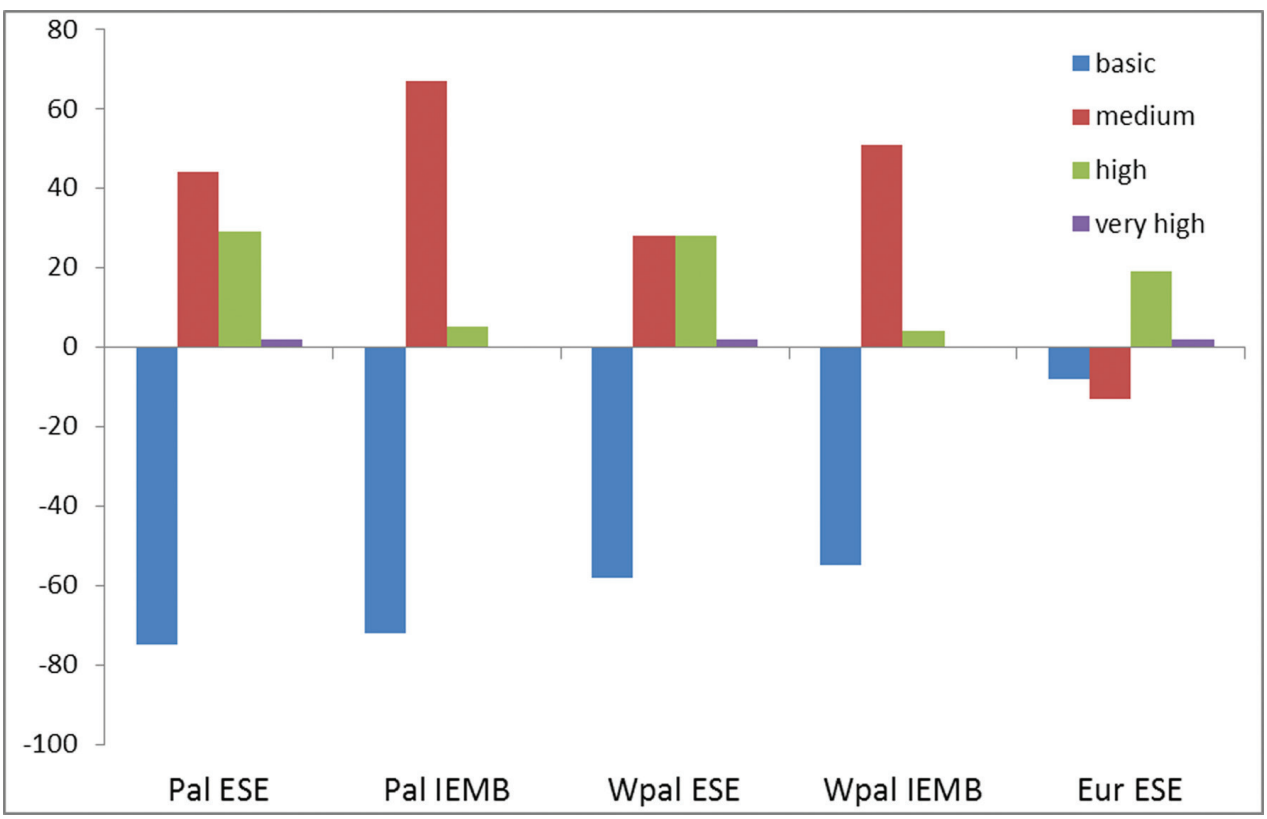

Figure 6. Differences in the National Responsibility-rank distribution between the assessments with Europe as reference area and the IEMB biogeographic map and the other 5 combinations (reference area: Pal $=$ Palearctis, $\mathbf{W P a l}=$ Western Palearctis, Eur = geographic Europe; maps: ESE = Environmental zones, IEMB = IEMB biogeographic map).

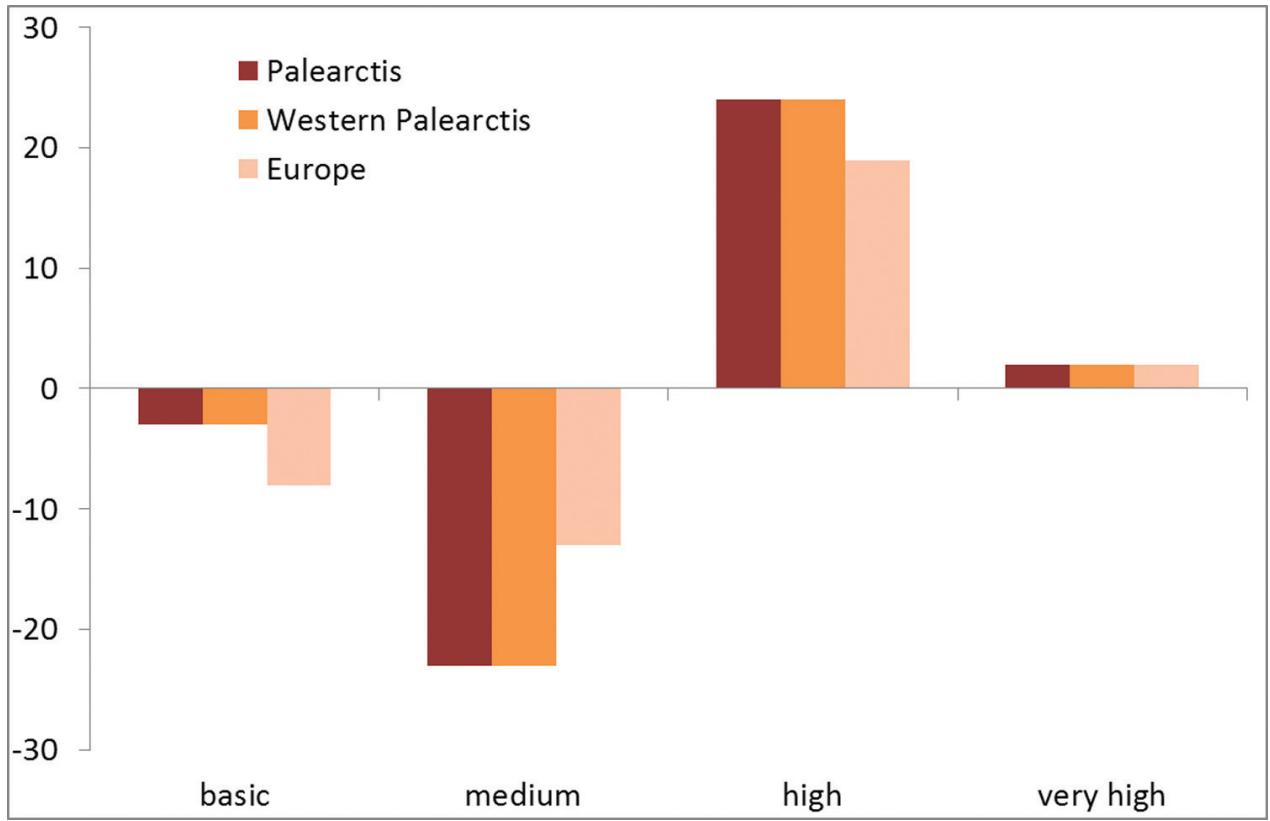

Figure 7. Shifts of the allocation of forest habitat types to responsibility classes when using the ESE versus the IEMB within each reference area. 
Mediterranean bioregion (ES, IT, FR, CY, PT). Changes were the least for countries in Central and Western Europe (BE, IE, LU, NL, PL, UK; Figure 8). We also found higher ranks with increasing size of the reference area (comparison of Palearctic Region to geographical Europe in Figure 9). The strongest shifts from basic to medium ranks were observed for AT, DK, FR, and IT.

A multiple regression of the differences in the rank "medium" between NR assessments based on the ESE map using as reference area the Palearctic region or geographical Europe $\left(F_{2,22}=6.899 ; p=0.005\right)$ showed a difference, but this difference was not explained by the size of a country $\left(t_{22}=-1.304 ; p=0.205\right)$. Differences were mainly driven by the number of habitats occurring within a country $\left(t_{22}=3.507 ; p=0.002\right)$.

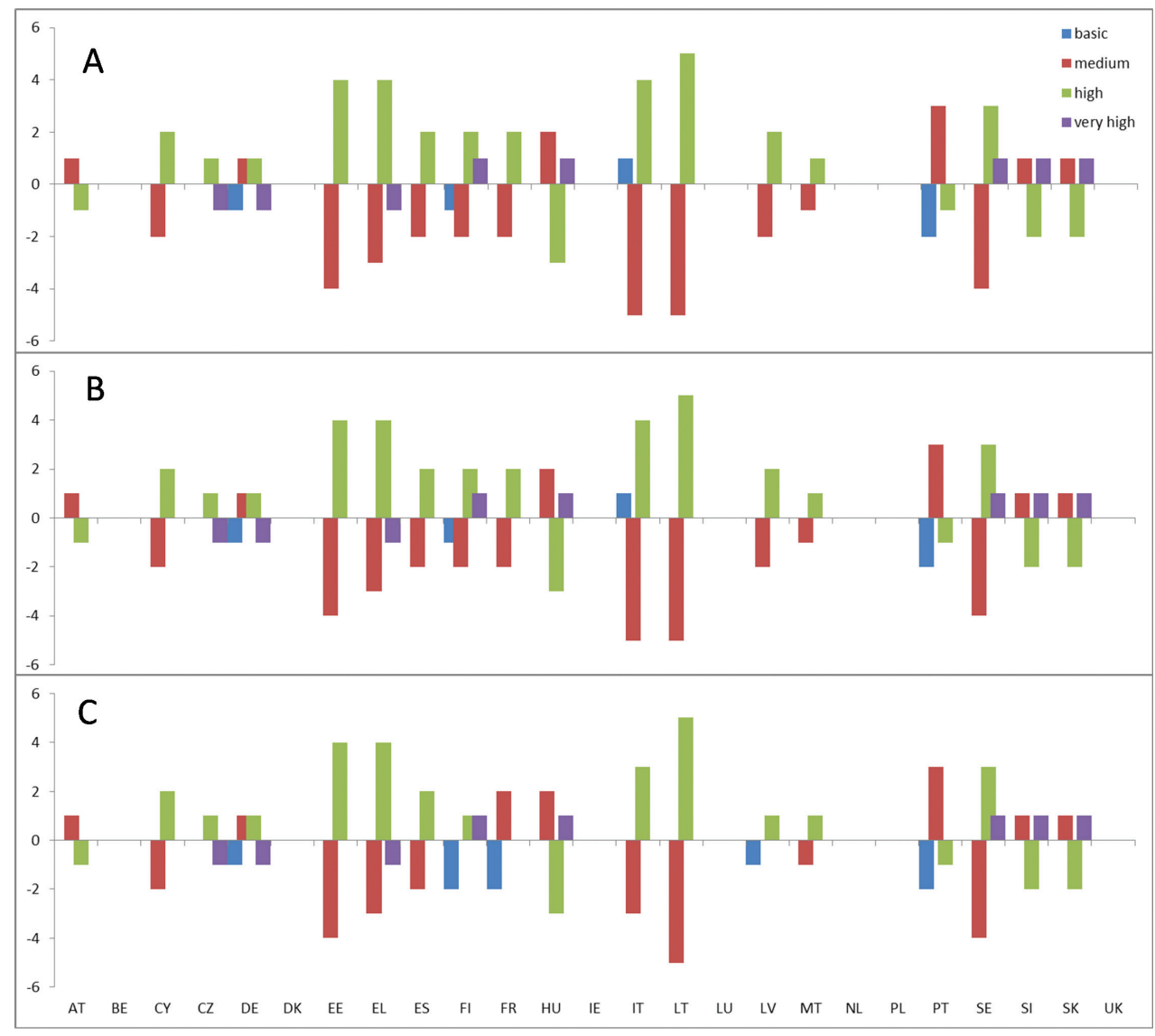

Figure 8. Shifts of the allocation of forest habitat types to responsibility classes per country when using the ESE versus the IEMB biogeographic map for the different reference areas: $\mathbf{A}=$ Palearctis; $\mathbf{B}=$ Western Palearctis; and $\mathbf{C}=$ Europe. The countries are abbreviated following the two-letter convention of the international community (ISO 3166-1 alpha-2 codes; $\mathbf{A T}=$ Austria, BE = Belgium, CY = Cyprus, CZ = Czech Republic, DE = Germany, DK = Denmark, EE = Estonia, ES $=$ Spain, FI = Finland, FR = France, GR = Greece, $\mathbf{H U}=$ Hungary, $\mathbf{I E}=$ Ireland, $\mathbf{I T}=$ Italy, $\mathbf{L T}=$ Lithuania, $\mathbf{L U}=$ Luxembourg, $\mathbf{L V}=$ Latvia, MT = Malta, NL = Netherlands, $\mathbf{P L}=$ Poland, $\mathbf{P T}=$ Portugal, $\mathbf{S E}=$ Sweden, $\mathbf{S I}=$ Slovenia, $\mathbf{S K}=$ Slovakia, $\mathbf{U K}=$ Great Britain). 


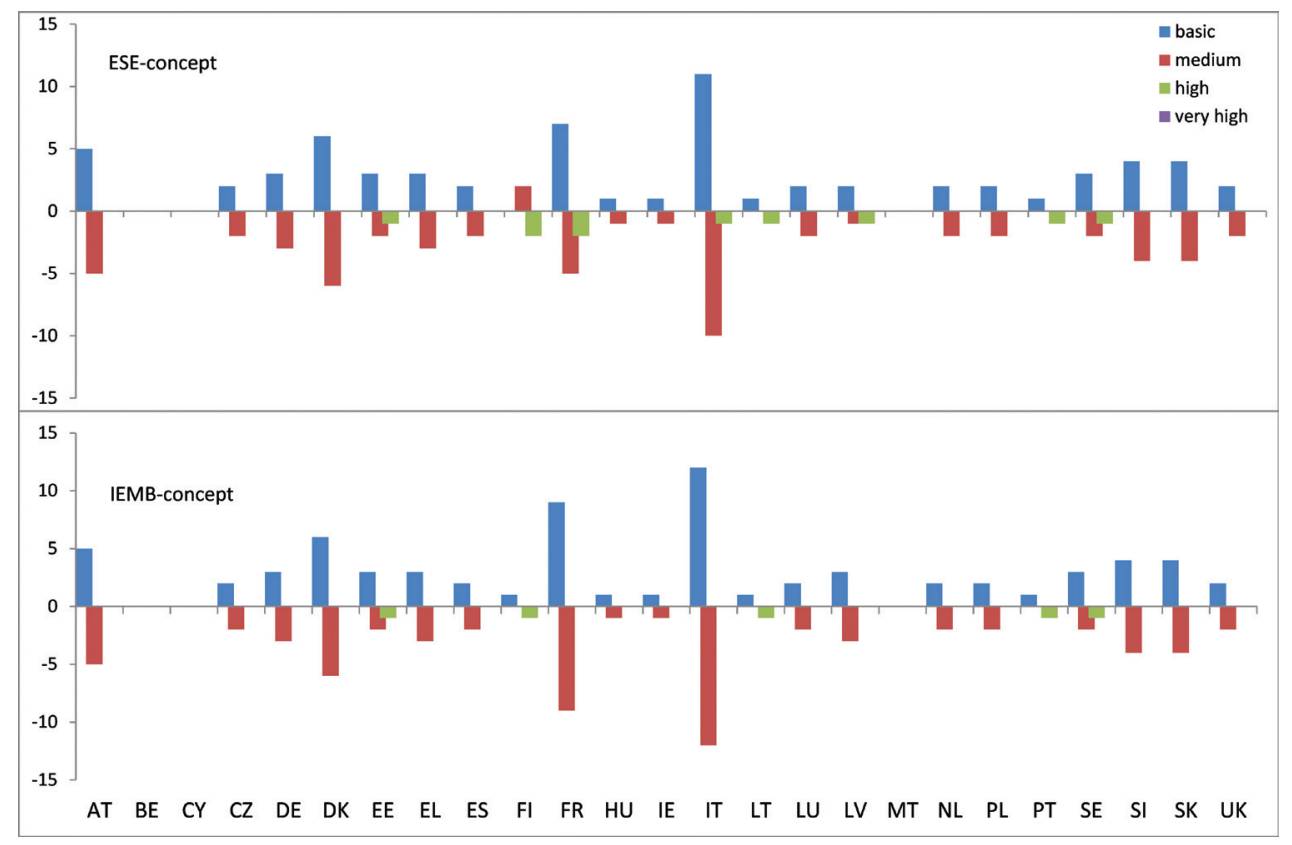

Figure 9. Shifts of allocations to ranks of national responsibility classes of countries when using the Palearctic versus Europe as reference area for the ESE and IEMB-maps. The countries are abbreviated following the two-letter convention of the international community (ISO 3166-1 alpha-2 codes; AT = Austria, $\mathbf{B E}=$ Belgium, $\mathbf{C Y}=$ Cyprus, $\mathbf{C Z}=$ Czech Republic, $\mathbf{D E}=$ Germany, $\mathbf{D K}=$ Denmark, $\mathbf{E E}=$ Estonia, $\mathbf{E S}=$ Spain, $\mathbf{F I}=$ Finland, $\mathbf{F R}=$ France, $\mathbf{G R}=$ Greece, $\mathbf{H U}=$ Hungary, $\mathbf{I E}=$ Ireland, $\mathbf{I T}=$ Italy, $\mathbf{L T}=$ Lithuania, $\mathbf{L U}=$ Luxembourg, $\mathbf{L V}=$ Latvia, $\mathbf{M T}=$ Malta, $\mathbf{N L}=$ Netherlands, $\mathbf{P L}=$ Poland, $\mathbf{P T}=$ Portugal, $\mathbf{S E}=$ Sweden, $\mathbf{S I}=$ Slovenia, $\mathbf{S K}=$ Slovakia, $\mathbf{U K}=$ Great Britain $)$.

\section{Discussion}

In the light of continuing decline of natural habitats (CBD 2010) and on-going biodiversity loss (Ricketts et al. 2005, Hoffmann et al. 2010), the commitment for nature protection legally defined in the Birds and Habitats Directives requires urgent implementation. As resources remain scarce, states are forced to determine their national responsibilities and set conservation priorities. Here we propose a method to determine national responsibilities for European habitat types, following a methodology initially developed for species (Schmeller et al. 2008b). The method was applied to 71 forest habitat types using three different reference areas and two different biogeographical maps. We found a shift to higher national responsibility ranks with increasing size of the reference area, due to an increasingly smaller ratio between reference area and total distribution area. We also observed a shift from medium to high national responsibility ranks when using the finer grained ESE (Metzger et al. 2005), as compared to the IEMB map. However, the lowest ("basic") and the highest rank ("very high") were little changed by the choice of biogeographical/environmental map. Further, our method was not directly influenced by the size of a country, but rather by the number of habitat types found within each country. 
The method proposed here, while scientifically sound and relatively robust, suffers from two main issues related to the conservation of habitat types, 1) the lack of a globally and even regionally accepted habitat classification, and 2) the limited availability of distribution data across biomes, such as the Western Palearctic or the Palearctic in general. The first point impacts on the method in two ways, firstly, it restricts its usability to habitats with the same definition standard, and secondly comparability of national responsibilities of habitats with the same definition may not be totally correct, as important elements can differ in habitat types found e.g. in northern or central Europe due to environmental or ecological drift (e.g. Ewald 2003). In addition, differing habitat definitions make it cumbersome to retrieve information on the total distribution area of a habitat type as well as it does impact on the monitoring of a habitat type per se (e.g. Mücher et al. 2009). If a habitat definition is unclear, monitoring data from different sources (e.g. national authorities responsible for nature conservation) may not be compatible. Further, if the same habitat has different names in the European Union than e.g. in Russia, the total distribution area is difficult to determine. From a conservation perspective, our method would overestimate the responsibilities for a habitat type in case we underestimate its complete distribution area or in case a habitat type definition has created a subtype of a habitat (hence it would be likely small and patchy). Hence, we consider our proposed method as conservative and thus applicable, at least to the European situation.

The aim of our method, however, is to create a globally applicable method to determine national responsibilities. Accepted habitat classifications and spatial information on their distribution are therefore urgently needed, as recommended in a recent article (Rodríguez et al. 2011). Once such data are available, we recommend the following addition to our methodology: A first biome-wide assessment of the distribution probability needs to be undertaken, comparing the expected and observed distribution probability of a habitat e.g. for Europe, the Middle East, and Asia. If the distribution probability is high, a finer scale assessment, with a reduced reference area (for habitats in Europe currently geographical Europe might be the best) needs to be done. This way, habitat types can be partitioned out between e.g. Europe, the Middle East and Asia, avoiding doing assessments of habitats with a very small part of their global distribution in the focal area.

In conclusion, the methodology to determine national responsibilities presented here is readily applicable to determine conservation responsibilities for habitats of the EU25 countries. It should be based on the environmental stratification of Europe (ESE; Metzger et al. 2005) and should use geographical Europe as the reference area due to limited data availability outside of Europe. For a fully comprehensive coverage of conservation needs, the national responsibilities for both species and habitats would need to be determined. Our method then provides a tool to allocate funds, direct conservation actions in the most sensible way, and point out data gaps (currently mainly the EU). Currently, distribution data is only available for the habitats of Annex I of the Habitats Directive but this is not based on a single habitat classification and the habitats are drawn from varying levels. Annex I also includes both habitat types and landscape units. Poor definitions and overlapping habitat types lead to frequent misinterpretations and data coherence needs to be improved to obtain a unified, logical 
and science-based classification of habitats for Europe and globally (see also Davies et al. 2004, ETC/BD 2008). Only with such a classification and distribution data will it be possible to determine national responsibilities for all habitat groups; the higher the standardization of the habitat classification and the quality of the (distribution) data, the higher the accuracy and reliability of the assessment. Generally, national responsibilities can be estimated based on any biogeographical map, although, due to politically influenced delineation of regions, small number of biogeographic regions, and interrelations with the chosen habitat classification, the application of the IEMB map leads to overall lower national responsibilities than the use of other maps. We do not consider this as an important problem, as the order of habitats in the priority list obtained by our methodology only changed in very few cases and because the two highest responsibility classes were rather robust to changes in the biogeographic map.

There are two more important problems, which need to be considered in the future, 1) the variability in the quality of a habitat and 2) the coherence of distribution data. The quality of a habitat type has not been homogeneously assessed across Europe, but may depend on management history, size, pollution and other factors. Our method can capture habitat quality by replacing the step on distribution pattern (as also suggested for the species method using abundance data) with a quality index. However, such data is not available widely and thus currently not applicable. Secondly, in the future, coherent distribution data, based on a consistent and complete habitat classification, should be gathered and made available across more countries than the EU25. Then, the methodology to determine national responsibilities has a unique potential to set, in combination with existing systems of threatenedness, such as Red Lists, conservation priorities (Schmeller et al. 2008a). It can contribute to effectively close gaps in habitat protection networks and prevent the further decline of natural habitat types, also beyond the European Union borders and would also emphasize the concept of biodiversity hotspots, while not ignoring habitats and species that do not occur in hotspots (Ernst et al. 2000).

\section{Acknowledgements}

This publication is a contribution from the project SCALES: Securing the Conservation of biodiversity across Administrative Levels and spatial, temporal, and Ecological Scales, funded under the European Union's Framework Program 7 (grant 226852; www. scales-project.net; Henle et al. 2010).

\section{References}

Becking R (1957) The Zürich-Montpellier school of phytosociology. The Botanical Review 23: 411-488. doi: 10.1007/bf02872328

Beissinger SR, Reed JM, Wunderle Jr JM, Robinson SK, Finch DM (2000) Report of the AOU conservation committee on the Partners in Flight species prioritization plan. The Auk 117:549-561. 
Brooks TM, Mittermeier RA, da Fonseca GAB, Gerlach J, Hoffmann M, Lamoreux JF, Mittermeier CG, Pilgrim JD, Rodrigues ASL (2006) Global Biodiversity Conservation Priorities. Science 313: 58-61. doi: 10.1126/science.1127609

Biondi E, Burrascano S, Casavecchia S, Copiz R, Del Vico E, Galdenzi D, Gigante D, Lasen C, Spampinato G, Venanzoni R, Zivkovic L, Blasi C (2012) Diagnosis and syntaxonomic interpretation of Annex I Habitats (Dir. 92/43/EEC) in Italy at the alliance level Plant Sociology 49: 5-37.

Bunce R, M. Bogers, M. Ortega, D. Morton, A. Allard, M. Prinz, J. Peterseil, R. Elena-Rossello, Jongman R (Eds) (2010) EBONE-Field Handbook. EBONE, Wageningen, Netherlands.

Bunce RGH, Bogers MMB, Evans D, Halada L, Jongman RHG, Mucher CA, Bauch B, de Blust G, Parr TW, Olsvig-Whittaker L (2012) The significance of habitats as indicators of biodiversity and their links to species. Ecological Indicators. doi: 10.1016/j.ecolind.2012.07.014

Carter MF, Hunter WC, Pashley DN, Rosenberg KV (2000) Setting conservation priorities for landbirds in the United States: the partners in flight approach. The Auk 117: 541-548.

Coates DJ, Atkins KA (2001) Priority setting and the conservation of Western Australia's diverse and highly endemic flora. Biological Conservation 97: 251-263. doi: 10.1016/ S0006-3207(00)00123-3

Commission of the European Communities CEC (1979) Council Directive 79/409/EEC of 2 April 1979 on the conservation of wild birds.

Commission of the European Communities CEC (1992) Council Directive 92/43/EEC of 21 May 1992 on the Conservation of Natural Habitats and of Wild Fauna and Flora.

Commission of the European Communities CEC (2006) Communication from the Commission - Halting the loss of biodiversity by 2010 - and beyond - Sustaining ecosystem services for human well-being. COM/2006/0216 final. http://eur-lex.europa.eu/LexUriServ/LexUriServ.do?uri=COM:2006:0216:FIN:EN:PDF

Commission of the European Communities CEC (2012) Our life insurance, our natural capital: an EU biodiversity strategy to 2020. 2011/2307(INI). See http://ec.europa.eu/environment/nature/biodiversity/comm2006/2020.htm

Convention of Biological Diversity (CBD), Secretariat (2010) Global Biodiversity Outlook 3. Montréal.

The Nature Conservancy (1988) Natural heritage program operations manual. The Nature Conservancy, Arlington, Virginia, USA, pp.

Couturier A (1999) Conservation Priorities for the Birds of Southern Ontario. Bird studies Canada, Port Rowan, Ontario, 15 pp.

Dasmann RF (1972) Towards a system for classifying natural regions of the world and their representation by national parks and reserves. Biological Conservation 4: 247-255. doi: 10.1016/0006-3207(72)90119-X

Dasmann RF (1974) Biotic provinces of the world: further development of a system for defining and classifying natural regions for purposes of conservation. IUCN Occasional Paper No 9. International Union for Conservation of Nature and Natural Resources, Morges (Switzerland).

Davies CE, Moss D, Hill MO (2004) EUNIS habitat classification revised 2004. Report to: European Environment Agency-European Topic Centre on Nature Protection and Biodiversity: 
Devillers P, Devillers-Teschuren J, Ledant JP (1991) CORINE biotopes manual. Habitats of the European Community. Office for Official Publications of the European Communities,Luxemburg.

Dinerstein E, Olson DM, Graham DJ, Webster AL, Primm SA, Bookbinder MP, Ledec G (1995) Conservation assessment of the terrestrial ecoregions of Latin America and the Caribbean. Banco Mundial, pp.

Eaton MA, Gregory RD, Noble DG, Robinson JA, Hughes J, Procter D, Brown AF, Gibbons DW (2005) Regional IUCN Red Listing: the process as applied to birds in the United Kingdom. Conservation Biology 19: 1557-1570. doi: 10.1111/j.1523-1739.2005.00213.x

Ernst D, Felinks B, Henle K, Klotz S, Sandermann H, Wieneke C (2000) HGF: Von der numerischen zur funktionellen Biodiversitat: Neue Forschungsansätze. GAIA - Ecological Perspectives for Science and Society 9: 140-145.

European Environment Agency (EEA) (2006) Biogeographical Regions, Europe 2005, http:// www.eea.europa.eu/data-and-maps/F50D9CF8-FFEE-475F-8A65-4E095512CBB7

European Enironment Agency (EEA) (2008) Biogeographical Regions, Europe 2008, http:// www.eea.europa.eu/data-and-maps/40B40BE1-5594-42F0-9494-CFF6FE0801C5

European Environment Agency. (EEA) (2009) Conservation status of habitat types and species (Article 17, Habitats Directive 92/43/EEC) http://www.eea.europa.eu/data-and-maps/ F6548631-2C53-423E-A104-69C0C920920F

European Topic Centre on Biological Diversity (ETC-BD) (2006) The indicative Map of European Biogeographical Regions: Methodology and development. Muséum National d'Histoire Naturelle, Paris.

European Topic Centre on Biological Diversity (ETC-BD) (2008) Habitats Directive Article 17 Report (2001 - 2006) - Data Completeness, Quality and Coherence http://forum. eionet.europa.eu/x_habitat-art17report/library/papers_technical/completeness_coherence_1/download/1/c_Data_completeness_quality_\%26_coherence_version\%201.pdf

Essl F, Egger G, Ellmauer T, Aigner S (2002) Rote Liste gefährdeter Biotoptypen ÖsterreichsWälder, Forste, Vorwälder. Monographien 156: 155.

Evans D (2010) Interpreting the habitats of Annex I: past, present and future. Acta botanica gallica 157: 677-686.

Evans D (2012) Building the European Union's Natura 2000 network. Nature Conservation 1: 11 - 26. doi: 10.3897/natureconservation.1.1808

Ewald J (2003) The calcareous riddle: Why are there so many calciphilous species in the Central European flora? Folia Geobotanica 38: 357-366. doi: 10.1007/bf02803244

Ewert F, Rounsevell M, Reginster I, Metzger M, Leemans R (2005) Future scenarios of European agricultural land use: I. Estimating changes in crop productivity. Agriculture, Ecosystems \& Environment 107: 101-116. doi: 10.1016/j.agee.2004.12.003

Fekete G, Molnar Z, Horvath F (1997) Description, identification key, and classification for habitats in Hungary and the National Habitat Classification System. Magyar Termszettudomajnyi Muzeum, Budapest.

Gärdenfors U (2000) Population viability analysis in the classification of threatened species: Problems and potentials. Ecological Bulletins 48: 181-190. 
Gärdenfors U (2001) Classifying threatened species at national versus global levels. Trends in Ecology and Evolution 16: 511-516. doi: 10.1016/S0169-5347(01)02214-5

Hall LS, Krausman PR, Morrison ML (1997) The habitat concept and a plea for standard terminology. Wildlife Society Bulletin 25: 173-182.

Hanski I, Pakkala T, Kuussaari M, Lei G (1995) Metapopulation persistence of an endangered butterfly in a fragmented landscape. Oikos 72: 21-28. doi: 10.2307/3546033

Henle K, Kunin WE, Schweiger O, Schmeller DS, Grobelnik V, Matsinos Y, Pantis J, Penev L, Potts SG, Ring I, Similä J, Tzanopoulos J, van den Hove S, Baguette M, Clobert J, Excoffier L, Framstad E, Grodinska-Jurczak M, Lengyel S, Marty P, Moilanen A, Porcher E, Storch D, Steffan-Dewenter I, Sykes MT, Zobel M, Settele J (2010) Securing the conservation of biodiversity across administrative levels and spatial, temporal, and ecological scales. GAIA 19/3: 187-193.

Henle K, Bauch B, Auliya M, Külvik M, Pe’er G, Schmeller DS, Framstad E (unpublished) Topical and spatial priorities for biodiversity monitoring: an assessment of European and global legislation tools and conventions. Ecological Indicators.

Hoffmann M, Hilton-Taylor C, Angulo A, Böhm M, Brooks TM, Butchart SHM, Carpenter KE, Chanson J, Collen B, Cox NA (2010) The impact of conservation on the status of the world's vertebrates. Science 330: 1503. doi: 10.1126/science.1194442

IUCN (1996) IUCN Red List of threatened animals. Gland, Switzerland - Cambridge, UK.

IUCN (2001) IUCN Red List categories and criteria: version 3.1. Gland, Switzerland - Cambridge, UK.

Jennings MD, Faber-Langendoen D, Loucks OL, Peet RK, Roberts D (2009) Standards for associations and alliances of the U.S. National Vegetation Classification. Ecological Monographs 79: 173-199. doi: 10.1890/07-1804.1

Keller V, Bollmann K (2001) For which bird species does Switzerland have a particular responsibility? Für welche Vogelarten trägt die Schweiz eine besondere Verantwortung? Ornithologische Beobachter 98: 323-340.

Keller V, Bollmann K (2004) From red lists to species of conservation concern. Conservation Biology 18: 1636-1644. doi: 10.1111/j.1523-1739.2004.00464.x

Kreft H, Jetz W (2010) A framework for delineating biogeographical regions based on species distributions. Journal of Biogeography 37: 2029-2053. doi: 10.1111/j.13652699.2010.02375.x

Magnusson WE (2004) Ecoregion as a pragmatic tool. Conservation Biology 18: 4-5. doi: 10.1111/j.1523-1739.2004.t01-1-00L13.x

McIntyre NE, Wiens JA (1999) Interactions between landscape structure and animal behavior: the roles of heterogeneously distributed resources and food deprivation on movement patterns. Landscape Ecology 14: 437-447. doi: 10.1023/A:1008074407036

Mehlman DW, Rosenberg KV, Wells JV, Robertson B (2004) A comparison of North American avian conservation priority ranking systems. Biological Conservation 120: 383-390. doi: 10.1016/j.biocon.2004.03.013

Metzger MJ, Bunce RGH, Jongman RHG, Mücher CA, Watkins JW (2005) A climatic stratification of the environment of Europe. Global Ecology \& Biogeography 14: 549-563. doi: 10.1111/j.1466-822X.2005.00190.x 
Metzger MJ, Schröter D, Leemans R, Cramer W (2008) A spatially explicit and quantitative vulnerability assessment of ecosystem service change in Europe. Regional Environmental Change 8: 91-107. doi: 10.1007/s10113-008-0044-x

Metzger MJ, Bunce RGH, Jongman RHG (2011) Top-level tiers for Global Ecosystem Classification and Mapping Initiative (GEOSS Task ED-06-02) WP3 Deliverable report D3.1 project EBONE FP, http://www.ebone.wur.nl/NR/rdonlyres/298E8A25-FEB4-4E0CB7E3-1C725D3F7006/125540/EBONED31_GEnS.pdf

Metzger MJ, Bunce RGH, Jongman RHG, Sayre R, Trabucco A, Zomer R (in press) A high resolution bioclimate map of the world: a unifying framework for global biodiversity research, Global Ecology and Biogeography.

Mittermeier RA, Myers N, Thomsen JB, Da Fonseca GAB, Olivieri S (1998) Biodiversity Hotspots and Major Tropical Wilderness Areas: Approaches to Setting Conservation Priorities. Conservation Biology 12: 516-520. doi: 10.1046/j.1523-1739.1998.012003516.x

Molnár Z, Bartha S, Seregélyes T, Illyés E, Botta-Dukát Z, Tímár G, Horváth F, Révész A, Kun A, János Bölöni (2007) A grid-based, satellite-image supported, multi-attributed vegetation mapping method (Á-NÉR). Folia Geobotanica 42: 225-247.

Moss D, Wyatt B (1994) The CORINE Biotopes Project: a database for conservation of nature and wildlife in the European Community. Applied Geography 14: 327-349. doi: 10.1016/0143-6228(94)90026-4

Mücher CA, Hennekens SM, Bunce RGH, Schamine JHJ, Schaepman ME (2009) Modelling the spatial distribution of Natura 2000 habitats across Europe. Landscape and urban planning 92: 148-159. doi: 10.1016/j.landurbplan.2009.04.003

Mucina L, Rodwell J, Schaminée J, Dierschke H (1993) European Vegetation Survey: Current state of some national programmes. Journal of Vegetation Science 4: 429-438. doi: $10.2307 / 3235603$

Olson DM, Dinerstein E, Hedao P, Walters S, Allnutt P, Loucks C, Kura Y, Kassem K, Webster A, Bookbinder M (2001a) Terrestrial Ecoregions of the Neotropical Realm (map). Conserv. Sci Program, WWF-US, DC.

Olson DM, Dinerstein E, Wikramanayake ED, Burgess ND, Powell GVN, Underwood EC, D'amico JA, Itoua I, Strand HE, Morrison JC (2001b) Terrestrial ecoregions of theworld: a new map of life on earth. BioScience 51:933-938. doi: 10.1641/0006-3568(2001)051 [0933:TEOTWA]2.0.CO;2

Ricketts TH, Dinerstein E, Boucher T, Brooks TM, Butchart SHM, Hoffmann M, Lamoreux JF, Morrison J, Parr M, Pilgrim JD (2005) Pinpointing and preventing imminent extinctions. Proceedings of the National Academy of Sciences of the United States of America 102: 18497. doi: 10.1073/pnas.0509060102

Riecken U (2006) Rote Liste der gefährdeten Biotoptypen Deutschlands: Zweite fortgeschriebene Fassung 2006. Bundesamt für Naturschutz, Bonn, Germany.

Rodríguez JP, Rodríguez-Clark KM, Baillie JEM, Ash N, Benson J, Boucher T, Brown C, Burgess ND, Collen B, Jennings M (2011) Establishing IUCN red list criteria for threatened ecosystems. Conservation Biology 25: 21-29. doi: 10.1111/j.1523-1739.2010.01598.x

Rodwell J, Pignatti S, Mucina L, Schaminée J (1995) European Vegetation Survey: update on progress. Journal of Vegetation Science 6: 759-762. doi: 10.2307/3236447 
Schmeller DS, Bauch B, Gruber B, Juskaitis R, Budrys E, Babij V, Lanno K, Sammul M, Varga Z, Henle K (2008a) Determination of conservation priorities in regions with multiple political jurisdictions. Biodiversity and Conservation 17: 3623-3630. doi: 10.1007/ s10531-008-9446-9

Schmeller DS, Gruber B, Bauch B, Lanno K, Budrys E, Babij V, Juskaitis R, Sammul M, Varga Z, Henle K (2008b) Determination of national conservation responsibilities for species conservation in regions with multiple political jurisdictions. Biodiversity and Conservation 17: 3607-3622. doi: 10.1007/s10531-008-9439-8

Schmeller DS, Gruber B, Budrys E, Framsted E, Lengyel S, Henle K (2008c) National responsibilities in European species conservation: A methodological review. Conservation Biology 22: 593-601. doi: 10.1111/j.1523-1739.2008.00961.x

Schnittler M (2004) Verantwortlichkeitsanalyse: Wie lassen sich Theorie und Naturschutzpraxis vereinen. Naturschutz und Biologische Vielfalt 8: 39-52.

Schnittler M, Günther KF (1999) Central European vascular plants requiring priority conservation measures: an analysis from national Red Lists and distribution maps. Biodiversity and Conservation 8: 891-925. doi: 10.1023/A:1008828704456

Schnittler M, Ludwig G, Pretscher P, Boye P (1994) Konzeption der Roten Listen der in Deutschland gefährdeten Tier- und Pflanzenarten - unter Berücksichtigung der neuen internationalen Kategorien. Natur und Landschaft 69: 451-459.

Schoene D, Killmann W, von Lüpke H, LoycheWilkie M (2007) Definitional issues related to reducing emissions from deforestation in developing countries. Forest and Climate Change Working Paper. Food and Agriculture Organization of the United Nations, Rome, Italy.

Tichý L (2002) JUICE, software for vegetation classification. Journal of Vegetation Science 13: 451-453. doi: 10.1111/j.1654-1103.2002.tb02069.x

Tillmann JE (2005) Habitat Fragmentation and Ecological Networks in Europe. GAIA - Ecological Perspectives for Science and Society 14: 119-123.

Traxler A, Minarz E, Englisch T, Fink B, Zechmeister H, Essl F (2005) Rote Liste der gefährdeten Biotoptypen Österreichs. Moore, Sümpfe und Quellfluren; Hochgebirgsrasen, Polsterfluren, Rasenfragmente und Schneeböden; Äcker, Ackerraine, Weingärten und Ruderalfluren; Zwergstrauchheiden; geomorphologisch geprägte Biotoptypen. Umweltbundesamt Wien - Monographien 174.

Udvardy MDF (1975) A classification of the biogeographical provinces of the world. International Union for Conservation of Nature and Natural Resources, Morges (Switzerland).

Whittaker RJ, Araujo MB, Paul J, Ladle RJ, Watson JEM, Willis KJ (2005) Conservation biogeography: assessment and prospect. Diversity and Distributions 11: 3-23. doi: 10.1111/j.1366-9516.2005.00143.x

Wiens JA, Schooley RL, Weeks RD (1997) Patchy landscapes and animal movements: Do beetles percolate? Oikos 78: 257-264. doi: 10.2307/3546292 


\section{Appendix}

Supplementary information to National responsibilities for conserving habitats - a freely scalable method. (doi: 10.3897/natureconservation.3.3710.app). File format: MS Word Document (docx).

Explanation note: The annex does provide a more detailed comparison of the different biogeographic maps. It further gives a list of all forest habitats given in the EU Habitats Direction.

Copyright notice: This dataset is made available under the Open Database License (http://opendatacommons.org/licenses/odbl/1.0/). The Open Database License $(\mathrm{ODbL})$ is a license agreement intended to allow users to freely share, modify, and use this Dataset while maintaining this same freedom for others, provided that the original source and author(s) are credited.

Citation: Schmeller DS, Maier A, Evans D, Henle K (2012) National responsibilities for conserving habitats - a freely scalable method. Nature Conservation 3: 21-44. doi: 10.3897/natureconservation.3.3710.app 